\title{
DRACHMAS IN SOLON'S LAWS.I. STATEMENT OF THE PROBLEM AND PRELIMINARY ANALYSIS OF THE KEY EVIDENCE
}

\author{
Igor E. Surikov
}

Institute of General History of the Russian Academy of Sciences, Russia, isurikov@mail.ru

Abstract. In a number of Solon's laws issued in 594/593 BC the drachmas were mentioned. These references were taken by all ancient authors of the Classical and subsequent periods as evidence of the existence of coinage in Athens in Solon's time. However, today, thanks to the efforts of numismatists, it has been proved beyond any doubt that in the first half of the $6^{\text {th }}$ century BC. Athens produced no coins. Thus, the question to be answered is what drachmas are being spoken about in Solon's laws. This first part of the article analyzes in some detail relevant pieces of evidence in the sources (they are mostly in Plutarch's Solon), so further, in the second part, it would be possible to suggest a conceptual decision on the basis of these empirical data.

Key words: Solon, Archaic Athens, law-making, coinage, drachmas, Plutarch

\section{ОПИСАНИЕ ПОЛИБИЕМ ВОЙНЫ МЕЖДУ АНТИОХОМ ІІІ И ЕВТИДЕМОМ I: ЦЕЛИ АВТОРА В КОНТЕКСТЕ ЕГО ПОЛИТИЧЕСКИХ ВОЗЗРЕНИЙ}

\section{А.А. Попов}

Санкт-Петербургский государственный институт культуры, Санкт-Петербург, artempopovspb@gmail.com

Аннотация. Статья посвящена описанию Полибием войны между селевкидским царем Антиохом III Великим и греко-бактрийским правителем Евтидемом I Богом, произошедшей около 208-206 гг. до н. э. Эти события описаны в его «Всеобщей истории», созданной во II в. до н. э. Автор этой работы рассматривает вопросы, посвященные политическим и философским целям Полибия при освещении данных событий, пытается их реконструировать.

Основываясь на описании битвы при Арии и Бактрийского похода, в целом, следует заметить явные черты восхваления Антиоха III со стороны Полибия. При этом в период столкновений на полях сражений и во время мирных переговоров с греко-бактрийским ца-

\footnotetext{
Попов Артем Анатольевич — кандидат исторических наук, доцент кафедры истории и петербурговедения Санкт-Петербургского государственного института культуры. E-mail: artempopovspb@ gmail.com
} 
рем этот представитель династии Селевкидов проявил себя как храбрый воин и рассудительный дипломат. Описание войны с Евтидемом I носит крайне важный идеологический характер для иллюстраций теоретических идей Полибия на практическом материале. Ведь в последующих частях своего сочинения этот античный автор критикует деяния этого селевкидского правителя и рисует его в виде одного из крупнейших тиранов своей эпохи, противопоставляя его Римской республиканске. В этой связи Бактрийская кампания лишь фон для описания личности Антиоха III.

Для понимания же полководческих и воинских талантов Антиоха III древний историк предлагает нам рассмотреть яркую картину пограничного сражения на реке Арий. Именно на примере этого эпизода этот царь рисуется Полибием как несомненный талант в области стратегии и тактики. Здесь на конкретных примерах, возможно частично реконструированных этим литератором, видны классические тактические приемы построения войска, оптимального применения различных родов войск в условиях молниеносного марша, форсирования водной преграды передовых отрядов и дальнейшей переправы всего остального войска с учетом одновременном противодействии крупных конных подразделений противника.

Ключевые слова: эллинистический период, Греко-Бактрия, Селевкиды, Полибий, битва на Арии, Антиох III, Евтидем I

Уже в XVIII в. Г.З. Байер использовал сведения Полибия, наряду с данными Страбона и Юстина, при описании истории правления греко-бактрийских и индо-греческих царей ${ }^{1}$. В ХХ в. в классических трудах У.В. Тарна ${ }^{2}$ и А.К. Нараин $^{3}$ также рассматривались вопросы, касающиеся сообщений этого выдающего античного историка о войне Антиоха III и Евтидема I (около 208-206 гг. до н. э.). В современной научной литературе, например, в работах В.П. Никонорова 4 или Дж. Лернера ${ }^{5}$, уделяется значительное внимание данным событиям. Однако в перечисленных выше трудах не был затронут отдельный сюжет, который касается идеологического контекста при описании Полибием указанного военного конфликта. Вслед за своими предшественниками автор данного исследования в своей отдельной публикации, посвященной походу Антиоха III в Бактрию, не рассматривал подобного вопроса ${ }^{6}$. Как он не рассматривал и в последующих работах, посвященных истории и культуре Греко-Бактрии в целом. Поэтому нижеследующий текст направлен на восполнение этого пробела.

Во «Всеобщей истории» Полибия затрагиваются сюжеты, связанные с различными странами и государствами античной эпохи. При первом же приближении к сохранившимся сведениям этого выдающегося греческого ученого и политика отчетливо заметно, что теме истории Бактрии периода эллинизма он уделяет незначительное внимание, ведь центральное место отводится Средиземноморью, Риму и эллинам. Бактрийские реалии той эпохи для него лишь побочный фон, на котором разыгрывается малая часть основного представления, режиссером которого он является.

\footnotetext{
1 Bayer 1738.

2 Tarn 1951.

3 Narain 1962.

4 Nikonorov 1997.

5 Lerner 1999.

6 Попов 2002.
} 
Известно, что Полибий - автор, относящийся к историческому методу весьма скрупулезно. Его источники - не плохо проверенные россказни, способные лишь завлечь читателя, но тщательно выбранный материал: свидетельства очевидцев событий, которые он описывает, документы, собственные наблюдения. При этом его собственный политический и военный опыт позволяет квалифицировать события с грамотных позиций практика. Достаточно рассмотреть его критические замечания по поводу творчества Тимея (Polyb. XII, 4a-28).

При этом Полибия нельзя назвать автором беспристрастным, как показал в своей статье А.Я. Тыжо ${ }^{7}$. Его «Всеобщая история» - всем известный памятник величию Римской республики эпохи Пунических войн. В то же время оппоненты Рима на политической арене древнего Средиземноморья и Причерноморья становятся для Полибия антиподами, которые противопоставляются его кумиру - Римскому государственному зданию.

Одним из таких антигероев является Антиох III Великий, выдающийся представитель династии Селевкидов. Начало его правления (223 г. до н. э.) было ознаменовано мощными потрясениями как внутри, так и за пределами империи потомков Селевка I Никатора (Polyb. V, 40). В середине III в. до н. э. фактическую независимость на востоке государства обрели Парфия и Бактрия, отпавшие от сирийских владык. В Восточном Средиземноморье бушевали Сирийские войны с египетским государством Лагидов. Даже при вступлении на престол Антиоху пришлось столкнуться с сепаратизмом. На востоке восстали сатрап Мидии Молон и сатрап Персии Александр, его брат. На западе отложился и возложил на себя царскую диадему его дядя Ахей, который узурпировал власть над малоазийскими провинциями, расположенными за Тавром (Polyb. V. 41). Одной из важнейших целей правления Антиоха стало собирание в единое мощное государство земель, некогда принадлежавших Селевкидам, в то время разрозненных и объятых пламенем усобицы. Молодому царю, еще не искушенному властью, и не столь опытному политику предстояла достаточно сложная задача.

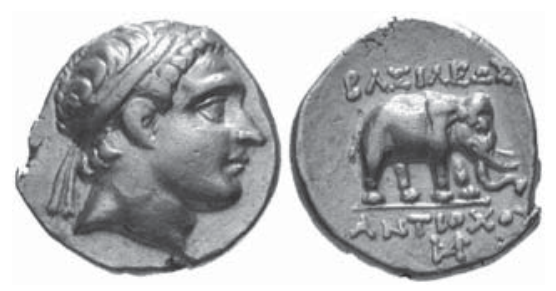

Рис. 1. Драхма Антиоха III ${ }^{8}$

В этой связи в череде его выдающихся и удачных свершений следует особо выделить его Восточный поход (212-205 гг. до н. э.). Он состоялся после разгрома сепаратистов и заключения мира с Птолемеем IV, царем Египта. По результатам восточной кампании Антиох был назван Великим. Одним из важнейших этапов этого похода была война с греко-бактрийским правителем Евтидемом I.

\footnotetext{
7 Тыжов 1994.

8 Houghton, Loeber 2002, No 1065-1.
} 


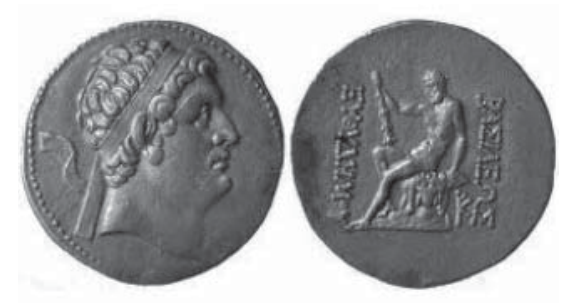

Рис. 2. Тетрадрахма Евтидема I

Сохранились два значительных отрывка из сообщений Полибия о противостоянии Антиоха и Евтидема (Polyb. X, 49; XI. 34). Примечательно, что оба эти пассажа завершают X и XI книги.

Чтобы адекватно оценивать характер и значение сведений Полибия о походе Антиоха в Бактрию стоит, во-первых, обозначить место этих пассажей в самой «Всеобщей истории», их смысловую и даже идеологическую роль.

B XV книге сочинения Полибия встречается два очень важных рассуждения о личности Антиоха. Эта часть труда историка заканчивается следующим выводом. В начале своего правления этот представитель династии Селевкидов проводил весьма позитивную политику. Антиох представляется в этот период своего царствования персоной с широкими способностями, готовым к осуществлению задуманных проектов, целеустремленным и смелым. Однако годы его изменили. Он превратился в дурного правителя. В этой связи не оправдались надежды, которые возлагались на него другими людьми (Polyb. XV, 37).

В середине этой книги Полибий раскрывает один из низменных и несправедливых, в его понимании, поступков Антиоха. Возможно, именно с него и началось моральное падение этого владыки. Это произошло после Восточного похода, который закончился в 205 г. до н. э. Так как Антиох и македонский царь Филипп подстрекали друг друга к разделу территорий малолетнего Птолемея V, они удостоились самой резкой критики со стороны Полибия. Здесь последний их сравнил с тиранами и рабами за посягательство на земли юного, еще неопытного властителя державы Лагидов (Polyb. XV, 20).

Здесь читатель «Всеобщей истории» Полибия узнает, в какой момент в Антиохе стали ярко проявляться черты развращенного самодержца, как он эволюционировал из царя в тирана.

В знаменитой VI книге Полибия, где говорится о политическом устройстве Рима и различных формах государства, встречается пассаж о царской власти и тирании (Polyb. VI, 6-7). Там излагается процесс преображения правильной формы самодержавной власти в извращенную. При этом это делается автором с позиций теоретика без конкретных исторических примеров.

Стоит отметить, что в этом смысле у Полибия, как автора, склонного к философским рассуждениям в духе стоицизма, вряд ли не было спланированного заранее описания личности Антиоха. В противном случае следует воспринимать сведения об этом монархе как об одном из рядовых исторических персонажей. При первом же взгляде на труд Полибия бросается в глаза, сколь много места в

\footnotetext{
9 Bopearachchi 1991, 157, pl. 3, ser. 9/13.
} 
нем отводится этому эллинистическому правителю. Полибий при описании событий старался соблюдать хронологию. Поэтому некоторые сведения об Антиохе разбросаны по разным частям работы этого историка. Однако, собрав все сообщения об Антиохе воедино, можно отчетливо увидеть, что этот селевкидский владыка стал для него примером и иллюстрацией одного из наиболее крупных тиранов эпохи Пунических войн. При этом Антиох здесь противопоставлен римлянам не только на полях сражений как полководец, но и с идеологической точки зрения как политическая фигура.

Интересен вопрос: когда же Антиох еще не мог быть назван такими эпитетами, как «тиран» и даже «раб», когда он, по мнению Полибия, сохранял еще достойный облик? Этот ответ находится в последних строках XI книги, в параграфе, описывающем окончание Восточного похода Антиоха (Бактрийскую и Индийскую кампании). Там великий греческий литератор пишет о том, что в результате этого похода народы не только Азии, но и Европы признали в нем личность, заслуживающую царской власти (Polyb. XI, 34). Недаром считается, что после этих событий Антиох был удостоен эпитета «Великий», которым владел великий македонский царь Александр. К тому же империя Селевкидов в тот момент достигла максимального могущества, спустя многие десятилетия после смерти Селевка Никатора.

Исходя из вышеизложенного, следует логичное заключение. Описание Полибием событий, произошедших с Антиохом в Бактрии и Индии (Polyb. X. 49; XI. $34)$, представляется крайне важным с идеологической точки зрения. Это важная часть «Всеобщей истории» и практическая иллюстрация идей Полибия в контексте его теоретических изысканий, описанных в VI книге указанного труда.

Война между Антиохом и Евтидемом, исходя из сохранившихся сведений Полибия, имеет два ключевых события: битва на Арии и осада Бактр. Река Арий протекала по границе Парфии и Бактрии. Бактры, располагавшиеся в долине Амударьи, являлись древней столицей Бактрии.

Полибий в своей X книге описывает события, связанные с 211-208 гг. до н. э. и происходившие во Вторую Пуническую войну. Как говорилось выше, параграф, где описываются события, связанные с началом похода Антиоха в Греко-Бактрию, является окончанием данной книги. В этой связи следует предположить, что битва на Арии и начало осады Бактр произошли самое позднее в 208 г. до н. э.

Разрыв в изложении о военных действий между Антиохом и Евтидемом связан с последовательным хронологическим изложением во «Всеобщей истории» Полибия. Война началась около 208 г. до н. э. с битвы на реке Арий. Однако осада столицы Евтидема Бактр (Зариаспы) затянулась на долгое время. Закончилось это противостояние мирным договором 206 г. до н. э. Примечательно и символично, что это событие, как и возобновление договора с индийским царем Софагасеном, произошло столетие спустя после заключения договора Селевка I Никатора с Чандрагуптой I, основателем династии Маурьев (305 г. до н. э.). В этой связи Антиох III уподобился своим походом не только Александру Великому, как отмечалось выше, но и своему предку Селевку Никатору, основателю его империи. При этом Антиох поступил, как и Селевк I, выдавший свою дочь замуж за Чандрагупту. В конечной фазе своего Восточного похода он договаривается о династическом бра- 
ке. Антиох по условиям договора с Евтидемом должен был выдать свою дочь за Деметрия, сына этого греко-бактрийского царя.

Если говорить о частностях, то мы отчетливо видим в сведениях Полибия об Антиохе в Бактрии черты восхваления этого селевкидского правителя.

Так, Полибий отмечает справедливость мирного договора с Евтидемом (206 г. до н. э.), а также разумный расчет. Ведь, лишив царской власти греко-бактрийского владыку в ходе возможной братоубийственной и кровопролитной войны за обладание владениями Евтидема, Антиох рисковал. Он мог подорвать свой авторитет царя-объединителя азиатских эллинов, проливая кровь во время осады Бактр. Также он мог соприкоснуться с варварскими кочевыми ордами, которые обрушились бы с северных границ царства Евтидема. В этом случае угроза была бы не только Бактрии, но и в том числе царству самого Антиоха. К тому же после заключения договора селевкидскому царю были переданы боевые слоны, бывшие у Евтидема, и обильные припасы для продолжения похода, а это было весьма необходимо для преодоления пути в Индию и возвращения на Ближний Восток (Polyb. XI, 34).

В начале войны, перед форсированием боевых действий, направленных против основных сил греко-бактрийского царя Евтидема, Антиох был занят осадой какого-то иранского города. Когда же до селевкидского царя дошло известие о том, что Евтидем с войсками находится в Тапурии, Антиох немедленно принимает решение об активизации наступательных операций по отношению к Бактрии.

В этой связи можно сказать, что Антиох решается застать своего противника врасплох. По-видимому, Евтидем не предполагал столь быстрой атаки своих владений в этом направлении со стороны селевкидского царя.

Однако встает вопрос о локализации войск Евтидема. Нам Полибий говорит о дислокации их в Тапурии. Это означает, что он дислоцировался в Табаристане, на юге Прикаспия. Были ли эти войска на Эльбурсе или в равнинной части - не имеет значения. Все равно: это находится весьма далеко на западе от Бактр (Зариаспы), столицы Евтидема.

Здесь видно, насколько благоразумно поступал Антиох. Действительно, приступать без разведки к переходу через полноводный Арий (Герируд) было опрометчиво. Ведь он мог встретить на противоположном берегу мощную армию, состоящую из эллинских отрядов и многочисленной местной конницы. Тогда ему пришлось бы изобретать различные способы переправы для своих войск. Скорее всего, здесь не обошлось бы без хитрости, которую применили когда-то Александр Великий при переходе через Гидасп или Ганнибал при форсировании Родана.

При этом Евтидем, по сведениям Полибия, после битвы на Арии укрылся в Бактрах. Таким образом, локализацию Евтидема в Тапурии непосредственно во время сражения на реке Арий вряд ли можно назвать реальной. Возможно, какието значительные контингенты и располагались в Прикаспии, так как греко-бактрийский царь мог производить какие-то военные операции на границе Парфии или же в непосредственной близости от скифских границ. Однако очевидно, что основным его форпостом, в частности в этом походе, должен был служить Мервский оазис. По сохранившимся археологическим памятникам и упоминанию о нем в античной литературе мы знаем, что Мерв был хорошо укреплен, прежде 
всего от вторжений со стороны кочевников. Достаточно вспомнить сообщение Страбона о том, что селевкидский царь Антиох I Сотер основал там город Антиохию и укрепил его стеной длиной в 1500 стадий (Strab. XI, 10, 2). В этой связи можно предположить, что северные номады могли прийти в движение в связи с ослаблением Парфии и Бактрии при вторжении войск Антиоха или Евтидем решил обезопасить свои границы в Прикаспии на случай нападения на Бактрию армии могущественного Селевкида.

Если упоминание Полибия о расположении Евтидема во главе своего войска в Тапурии во время начала войны с Антиохом является верным, тогда следует предположить, что Мервский оазис находился под властью греко-бактрийского царя. Странно было бы предположить, что Евтидем не знал о происходящих в Иране событиях, о том, что Антиох покоряет своей воле парфян. В случае же нахождения в Южном Прикаспии вряд ли бы он оставил в своем тылу, между Каспийским морем и Бактрами, враждебный, хорошо укрепленный и богатый природой населенный пункт.

В любом случае разведка Антиоха, о которой говорится в этом пассаже, не могла доставить информацию об Евтидеме и его кампании в Тапурии (Табаристане) в течение быстрого времени. Когда же Евтидем узнал о возможном вторжении Антиоха и его продвижении в парфянских пределах, он смог выслать к своим западным границам лишь передовой конный отряд и тем самым хоть на какое-то время отсрочить осаду Бактр, до которых ему пришлось добираться с остальным войском ускоренными маршами. По-видимому, в момент переправы Антиоха через Арий (Герируд) он уже мог быть на полпути к Бактрам, но воспрепятствовать переправе через указанную водную преграду ему самому уже не удалось. Скорее всего, Евтидем в тот временной промежуток располагался с основными воинскими контингентами в районе Мерва. Возможно, продвижение его армии шло по течению реки Муграб, которую эллины называли Маргом. В дальнейшем, по-видимому, он планировал из долины Муграба совершить переход через Папопамиз и подойти к реке Герируд. Однако таковым замыслам не удалось сбыться, если, конечно, такие присутствовали.

Относительно того, что указанная река Арий является рекой Герируд, сомнений нет. Существует ее вполне четкое описание у Страбона (Strab. XI. 10. 1-2; 11. 5), которое указывает на данный факт.

Поход Антиоха к границам владениям Евтидема с того момента, когда он снял осаду с неуказанного Полибием иранского укрепленного населенного пункта, до долины Герируд занял три дня. При этом античный автор подчеркивает, как мудро Антиох распорядился ими. Первые два дня он прошел не торопясь, видимо, давая возможность войскам полноценно отдыхнуть перед предстоящим сражением. Вечером накануне третьего дня пути и, таким образом, битвы он приказал выступать на рассвете основным силам. Сам же, взяв конницу, легковооруженных и десять тысяч пелтастов, ночью ускоренным маршем преодолел оставшееся расстояние до реки Герируд. Дорога Антиоха пролегала по равнинной местности и была удобна для конных подразделений. Он смог форсировать эту водную преграду, переправив на рассвете большую часть войска. Антиох знал, что конница бактрийцев, днем охраняющая свой берег реки, на ночь удаляется в близлежащий город, который располагался в не менее двадцати стадиях оттуда (Polyb. X, 49). 
С точки зрения военного искусства диспозиция битвы при Гранике очень похожа и одновременно не похожа на битву при Арии. Схожа она в задачах, то есть основная цель бактрийцев, как и персов, состояла в том, чтобы не допустить переправы врага. И расходится она, прежде всего, тем, что, в отличие от Александра III Великого, Антиох III Великий поступил по всем правилам военного искусства, совершив тактически верную переправу на рассвете. Здесь стоит отметить разницу характеров этих двух великих полководцев. Александр при Гранике был движим стремлением ошеломить противника своей во многом дерзкой атакой, а Антиох поступил расчетливо, как поступил бы Парменион на месте Александра. Ведь умудренный опытом Парменион советовал Александру осуществить переправу через Граник на рассвете, когда берег, где стояли персы, будет пуст из-за того, что те не останутся ночевать у реки, а отойдут на ночлег в более безопасное место, так как по количеству пехоты македоняне превосходили противника и могли ночью осуществить нападение на спящего врага (Arr. Anab. I, 13, 3). Таким образом, верность тактики Пармениона оказалась подтверждена Антиохом на практике.

Бактрийские разведчики известили основные силы о переправе селевкидских войск, и десятитысячный конный корпус обрушился на войска Антиоха, которые еще не успели окончательно выстроиться в правильный боевой порядок. В этот решающий момент царь смог правильно оценить обстановку и, благодаря верному расчету и личному мужеству, грамотно распорядиться бывшими в наличии у него отрядами (Polyb. X, 49).

Осознание крайней опасности привело Антиоха к мнению, что личный пример и боевая выучка лучших отрядов своего войска способны к решению задачи сдерживания огромных масс конницы противника. Под своим руководством он ввел в дело в качестве передового отряда две тысячи воинов, «которые в битвах обычно находились рядом с ним» (Polyb. X, 49).

Это означало, что селевкидский царь повел на врага свою агему. Она использовалась в качестве охраны и состояла из наиболее элитных подразделений. Своего рода гвардия в столь значительных количествах эллинам была известна многие века не только по своей собственной практике, но они знали и об аналогичных войсках у других народов. Корпус из десяти тысяч «бессмертных» со времен Дария I существовал у Ахеменидов. Широко использовались отряды «друзей» («гетайров») Александром Великим. Причем часто именно эти подразделения выполняли самые ответственные поручения на поле брани. Из их среды выходили не только офицеры младшего и среднего звена, но и полководцы, своего рода генералитет эллинистических армий. Часто наиболее выдающиеся по своим интеллектуальным и организаторским способностям представители таких войск становились управленческой элитой государства. Недаром в государстве Селевкидов понятие «друг» превратилось в титул с разветвленной иерархией, в добавлении к которому в этой державе появились еще так называемые «родственники» разных уровней. В итоге мы видим перед собой не просто царскую агему, а полк, состоящий из представителей элиты государства Селевкидов, и в продвижении по карьерной лестнице, и лично заинтересованных в победах своего монарха. В этой связи, безусловно, им выпал шанс проявить себя в деле, располагаясь в непосредственной близости от царя. Невольно вспоминается подвиг Клита Черного, спасшего Александра в битве при Гранике. Недаром впоследствии именно ему Александр 
доверял самые ответственные задания, зная о его преданности и чувстве долга. Возможно, окружавшие Антиоха верные воины-гвардейцы только и мечтали показать свою верность и виртуозное владение клинком, памятуя о события у вод быстротекущего Граника.

Примечательно, что Полибий отмечает с долей предположения исключительную доблесть самого Антиоха, превзошедшую всех воинов передового отряда. Автор отмечает, что «более всего этой битве он обязан славой храброго воина» (Polyb. X, 49). И опять здесь Полибий, скорее всего, предполагал аналогию с битвой при Гранике и исключительной храбростью Александра, граничащей даже с безрассудством. Однако в случае с Антиохом данное проявление мужества кажется оправданным и, более того, спасительным. В некотором смысле здесь автор «Всеобщей истории» мог руководствоваться стоической моралью и в некоторой степени совершить историческую реконструкцию, нежели излагать стопроцентные факты. Поэтому как он, так и мы о личных проявлениях исключительной храбрости Антиоха в битве при Арии (Герируде) должны говорить, прибавляя «по-видимому». Однако сомнения могут развеяться частично или полностью после одной из ремарок Полибия о результатах этого сражения, в которой говорится, что Антиох был ранен в ходе битвы в рот и потерял несколько зубов, его лошадь от ран, полученных в бою, умерла (Polyb. X, 49). Подобные факты вряд ли могли быть додуманы или сфальсифицированы. Полибий не отличался таким стилем изложения материала. Ведь стоическая мораль, проповедовавшая проявление мужества в критических ситуациях на поле битвы, существовала и впоследствии. Образы Марка Аврелия, ведущего свои легионы в атаку, или Юлиана Отсупника, погибшего при спасении рядовых воинов, всегда предстают перед историками, изучающими античное прошлое.

Известно, что агема выдержала натиск первого отряда конных бактрийцев, а перед нажимом остальных двух гвардейцы стали отступать. И действительно, две тысячи воинов, противостоящие в пять раз превосходящему противнику, скорее всего могли начать медленное отступление к основным силам селевкидской армии. К тому же мы знаем, что в этот момент в тылу этой части войска остальные отряды по приказу Антиоха выстраивались в правильный боевой порядок отдельными пешими и конными подразделениями. Когда же селевкидская кавалерия по большей части была приведена в боевую готовность, Панэтол, сподвижник и полководец Антиоха, отдал приказ о контрнаступлении (Polyb. X, 49).

Увлекая за собой отряд, в котором находился сам царь, Панэтол принудил бактрийцев, «нападавших нестройной толпой», отступить и покинуть место сражения посредством бегства. При этом бактрийцы потеряли значительную часть своих воинов (Polyb. X, 49).

При этом стоит вопрос, из каких родов войск состояла агема. Скорее всего, данный царский полк имел как пешие, так и конные отряды. Подобное деление на пехоту и конницу было и у «друзей» Александра Великого. Все они должны были иметь тяжелое вооружение эллинского и македонского образца. Таким образом, закованные в панцири и вооруженные длинными копьями воины Антиоха были способны сдержать натиск превосходящего противника, наступавшего «нестройной толпой», то есть, вероятнее всего, конной лавой, разбитой на три отряда. В пользу того, что в данном полку были многочисленные всадники, указы- 
вают два сообщения Полибия. Первое говорит о том, что сам Антиох сражался на коне. Второе повествует о том, что при ответной атаке селевкидской конницы под командованием Панэтола царь и окружавшие его воины присоединились к этим конным подразделениям. Вряд ли такое могло произойти, если бы солдаты, бывшие рядом с селевкидским владыкой, были бы исключительно пешими. Однако в этом передовом отряде, очевидно, могли быть и пехотинцы. В ходе подобных операций античные полководцы зачастую использовали тяжеловооруженную и опытную часть пешего войска. Так было при Гранике и при Гидаспе у Александра. Цезарь бросил смешанный строй конницы и пехоты против всадников Помпея при Фарсале. Именно правильное пешее построение часто давало возможность удержать позицию даже при наступлении превосходящих конных сил противника. В этот момент Антиох проявил себя грамотным полководцем с тактической точки зрения.

Также стоит вопрос, почему бактрийский отряд не укрылся в городе, где он располагался на ночлег. Видимо, это было обусловлено тонкостями маневров вооруженных сил обеих сторон. Со стороны Антиоха кавалерия преследовала и истребляла отступающих конных бактрийцев. При этих обстоятельствах большие массы конницы (в начале сражения десять тысяч всадников) вряд ли могли бы быстро отступить в городские пределы, за укрепления (предположим, через ворота) без потерь и без опасности впустить противника внутрь городских стен на своих плечах. К тому же присутствовала опасность попасть в западню после окружения данного поселения и осады его. Поэтому остатки разбитого конного корпуса направили своих скакунов в сторону основных сил Евтидема.

Подытоживая, стоит отметить, что описание Полибием войны Антиоха III c Евтидемом I напоминает панегирик этому селевкидскому монарху. При этом повествование великого историка о последующих деяниях этого царя выглядит как вынесение ему обвинительного приговора.

\section{ЛИТЕРАТУРА}

Попов, А.А. 2002: Поход Антиоха III в Греко-Бактрию (208-206 гг. до н. э.). Пара беллум (Para bellum) 15, 95-104.

Тыжов, А.Я. 1994: Полибий и его «Всеобщая история». В кн.: Полибий, Всеобщая история. Т. 1. СПб., 5-33.

Bayer, Th.S. 1738: Historia regni Graecorum Bactriani. Petropoli. Paris.

Bopearachchi, O. 1991: Monnais gréco-bactriennes et indo-grecques. Catalogue raissonè.

Houghton, A., Loeber, C. 2002: Seleucid Coins: A Comprehensive Catalogue. Part I. Vol. 1-2. New York -Lincoln-London.

Lerner, J.D. 1999: The impact of Seleucid decline on the Eastern Iranian Plateau: the foundations of Arsacid Parthia and Graeco-Bactria. Stuttgart.

Narain, A.K. 1962: The Indo-Greeks. Oxford.

Nikonorov, V.P. 1997: The Armies of Bactria (700 BC - 450 AD). Vol. 1-2. Stockport.

Tarn, W.W. 1951: The Greeks in Bactria and India. Cambridge. 
Popov, A.A. 2002: Pokhod Antiokha III v Greko-Bactriyu (208-206 BC). Para bellum 15, 95-104.

Tyzhov, A.Ya. 1994: Polibiy i ego «Vseobshchaya istoriya». In: Polibiy, Vseobshchaya istoriya. Vol. 1. 5-33.

Bayer, Th.S. 1738: Historia regni Graecorum Bactriani. Petropoli. Paris.

Bopearachchi, O. 1991: Monnais gréco-bactriennes et indo-grecques. Catalogue raissonè.

Houghton, A., Loeber, C. 2002: Seleucid Coins: A Comprehensive Catalogue. Part I. Vol. 1-2. New York- Lincoln-London.

Lerner, J.D. 1999: The impact of Seleucid decline on the Eastern Iranian Plateau: the foundations of Arsacid Parthia and Graeco-Bactria. Stuttgart.

Narain, A.K. 1962: The Indo-Greeks. $2^{\text {nd }}$ ed., Oxford.

Nikonorov, V.P. 1997: The Armies of Bactria (700 BC-450 AD). Vol. 1-2. Stockport.

Tarn, W.W. 1951: The Greeks in Bactria and India. $2^{\text {nd }}$ ed. Cambridge.

\section{POLYBIUS' STORY ABOUT THE WAR BETWEEN ANTIOCHUS III AND EUTHYDEMUS I: AUTHOR'S TARGETS IN THE CONTEXT OF HIS POLITICAL IDEAS}

\section{Artem A. Popov}

St.Petersburg State University of Culture, Russia,
artempopovspb@gmail.com

Abstract. The article is dedicated to Polybius' overview of the war between the Seleucid king Antiochus III the Great and the Greco-Bactrian ruler Euthydemus I the God happened circa 208-206 BC. These events are illustrated in his Histories created in the $2^{\text {nd }}$ century BC. The author of this article considers issues connected with the Polybius' the political and philosophic purposes in recital of these events, makes an attempt of their reconstruction.

In the Battle of the Arius description and the Bactrian campaign by Polybius, one can see the author praises Antiochus III. This Seleucid dynasty's representative during the collusions on the battlefields and during the peace negotiations with the Greco-Bactrian king proved himself as a brave warrior and a wise diplomat. The description of the war with Euthydemus I has an extremely important ideological meaning for the illustrations of Polybius' theoretical ideas based on the practical material. After all this ancient author criticizes in next parts of his work this Seleucid ruler's deeds and depicts him as one of the greatest tyrant of that epoch, opposed him to the Roman Republic. Thereupon the Bactrian campaign is just the background of the depiction of Antiochus' III personality.

To understand Antiochus' III commander and war talents the ancient author offers us to view the bright scene of the frontier struggle on the Arius. Exactly here Polybius depicts Antiochus III as the absolute talent in strategic and tactics. Here one can see on the concrete examples, perhaps they were reconstructed by this literary man, the classical tactic positions of the forces formation, the optimal use of the different kinds of army by the flash-like march, the water barrier forcing and the following crossing of the remaining army by the enemy simultaneous resistance of the large horse regiments.

Key words: the Hellenistic period, Greco-Bactria, Seleucids, Polybius, the Battle of the Arius, Antiochus III, Euthydemus I 